University of Montana

ScholarWorks at University of Montana

\title{
Understanding Abundance Patterns of a Declining Seabird: Implications for Monitoring
}

\author{
Michelle L. Kissling \\ Mason Reid \\ Paul M. Lukacs \\ University of Montana - Missoula, paul.lukacs@umontana.edu \\ Scott M. Gende \\ Stephen B. Lewis
}

Follow this and additional works at: https://scholarworks.umt.edu/wildbio_pubs

Part of the Life Sciences Commons

Let us know how access to this document benefits you.

\section{Recommended Citation}

Kissling, Michelle L.; Reid, Mason; Lukacs, Paul M.; Gende, Scott M.; and Lewis, Stephen B., "Understanding Abundance Patterns of a Declining Seabird: Implications for Monitoring" (2007). Wildlife Biology Faculty Publications. 68.

https://scholarworks.umt.edu/wildbio_pubs/68

This Article is brought to you for free and open access by the Wildlife Biology at ScholarWorks at University of Montana. It has been accepted for inclusion in Wildlife Biology Faculty Publications by an authorized administrator of ScholarWorks at University of Montana. For more information, please contact scholarworks@mso.umt.edu. 


\title{
UNDERSTANDING ABUNDANCE PATTERNS OF A DECLINING SEABIRD: IMPLICATIONS FOR MONITORING
}

\author{
Michelle L. Kissling, ${ }^{1,6}$ Mason Reid, ${ }^{2}$ Paul M. Lukacs, ${ }^{3}$ Scott M. Gende, ${ }^{4}$ and Stephen B. Lewis ${ }^{5}$ \\ ${ }^{1}$ U.S. Fish and Wildlife Service, 3000 Vintage Boulevard, Suite 201, Juneau, Alaska 99801 USA \\ ${ }^{2}$ National Park Service, Wrangell-St. Elias National Park and Preserve, P.O. Box 439, Copper Center, Alaska 99573 USA \\ ${ }^{3}$ Colorado Division of Wildlife, 317 W. Prospect Road, Fort Collins, Colorado 80526 USA \\ ${ }^{4}$ National Park Service, Glacier Bay Field Station, 3100 National Park Road, Juneau, Alaska 99801 USA \\ ${ }^{5}$ Alaska Department of Fish and Game, Division of Wildlife Conservation, P.O. Box 240020, Douglas, Alaska 99824 USA
}

Abstract. The Kittlitz's Murrelet (Brachyramphus brevirostris) is a rare, non-colonial seabird often associated with tidewater glaciers and a recent candidate for listing under the Endangered Species Act. We estimated abundance of Kittlitz's Murrelets across space and time from at-sea surveys along the coast of Alaska (USA) and then used these data to develop spatial models to describe abundance patterns and identify environmental factors affecting abundance. Over a five-week period in the summer of 2005, we recorded 794 Kittlitz's Murrelets, 16 Marbled Murrelets (B. marmoratus), and 70 unidentified murrelets. The overall population estimate ( $N$, mean \pm SE) during the peak period (3-9 July) was $1317 \pm 294$ birds, decreasing to $68 \pm 37$ by the last survey period (31 July-6 August). Density of Kittlitz's Murrelets was highest in pelagic waters of Taan Fjord $\left(18.6 \pm 7.8\right.$ birds $/ \mathrm{km}^{2}$, mean $\pm \mathrm{SE}$ ) during 10-16 July. Spatial models identified consistent "hotspots" of Kittlitz's Murrelets, including several small areas where high densities of murrelets were found throughout the survey period. Of the explanatory variables that we evaluated, tidal current strength influenced murrelet abundance most consistently, with higher abundance associated with strong tidal currents. Simulations based on the empirically derived estimates of variation demonstrated that spatial variation strongly influenced power to detect trend, although power changed little across the threefold difference in the coefficient of variation on detection probability. We include recommendations for monitoring Kittlitz's Murrelets (or other marine species) when there is a high degree of uncertainty about factors affecting abundance, especially spatial variability.

Key words: abundance patterns; Brachyramphus brevirostris; detection probability; endangered species; environmental factors; Icy Bay, Alaska, USA; Kittlitz's Murrelet; seabird monitoring; spatial modeling; tidal current.

\section{INTRODUCTION}

The most common objective of current wildlife monitoring programs is the detection of significant change in population distribution and abundance. Detecting declines in wildlife populations is of particular importance because conservation actions are often necessary to ensure persistence of the species. However, reliability of the estimated decline requires consideration of the biological and physical factors that influence the distribution of wildlife at different temporal and spatial scales. Known sources of variability can then be accounted for in estimation of trend, increasing precision and allowing for stronger inferences about the population in question.

In marine systems, environmental processes influence spatial gradients over hourly (e.g., tides), daily, seasonally (e.g., upwelling), yearly, or multiyear (e.g., Pacific

Manuscript received 29 November 2006; revised 12 April 2007; accepted 1 May 2007. Corresponding Editor: J. M. Marzluff.

${ }^{6}$ E-mail: michelle_kissling@fws.gov
Decadal Oscillations) time intervals, while other gradients such as bathymetry remain relatively constant (Rachowicz et al. 2006). Marine ecosystems with active tidewater glaciers are especially dynamic as a result of ice calving and flows and large inputs of freshwater, with subsequent changes in water column structure and mixing. When monitoring species associated with these dynamic environmental conditions, failure to account for spatial and temporal variation in physical and biological gradients can result in highly imprecise estimates of abundance and trend that can be difficult to interpret. Spatial models can be used to identify relationships between abundance and spatial variables that influence abundance over time (Hedley and Buckland 2004). These models also can be used to predict animal abundance as a function of environmental factors, which is particularly valuable for rare or uncommon species that occur in clumped distributions (e.g., Gomez de Segura et al. 2007).

The Kittlitz's Murrelet (Brachyramphus brevirostris; see Plate 1) is one of the rarest and least understood seabirds in the world. Endemic to Alaska and Russia, 


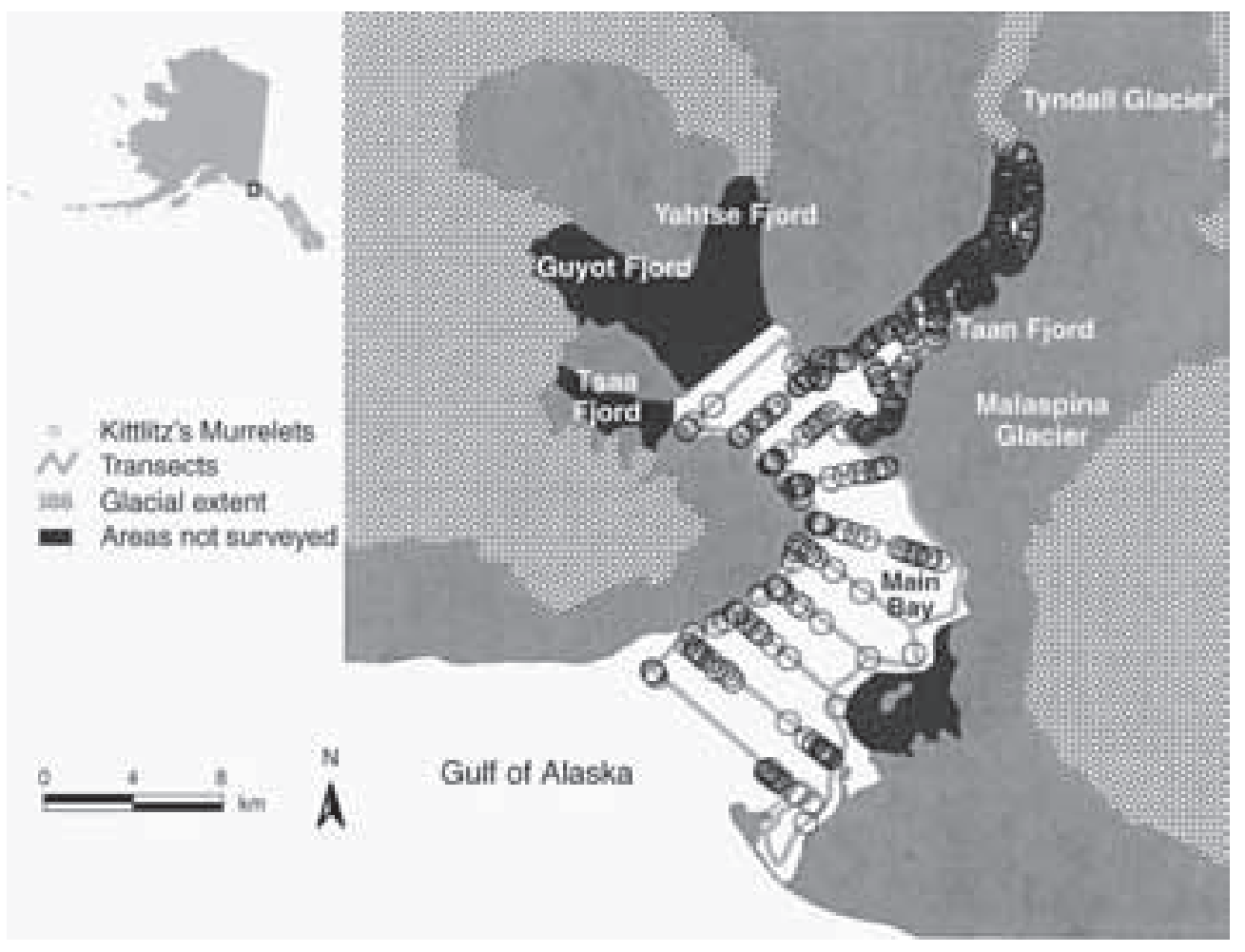

FIg. 1. Map of Icy Bay, Alaska, USA, with distribution of pelagic and shoreline transects and cumulative locations of AHY (after-hatch-year) Kittlitz's Murrelets recorded during this study, July 2005. Areas not surveyed regularly due to ice conditions or shallow waters are indicated in black.

this non-colonial species seems to be restricted to tidewater glaciers, glaciated fjords, outflows of glacial streams, and recently deglaciated areas during the breeding season (Day et al. 1999, 2003, Kuletz et al. 2003). Given the bird's apparent dependence on glacialinfluenced habitats, recent and rapid retreat of Alaska's glaciers (Arendt et al. 2002) has raised concerns for the fate of this species. Based on results of at-sea surveys in four core population areas, Kittlitz's Murrelets have declined up to $84 \%$ over the last 11 years and up to $18 \%$ per year (U.S. Fish and Wildlife Service 2005). In response to documented declines, the U.S. Fish and Wildlife Service listed the Kittlitz's Murrelet as a candidate species under the Endangered Species Act in May 2004 (69 FR 24875-24904). Speculated causes for decline include oil pollution, glacial recession, gill-net mortality, and reduced availability of preferred forage fish (van Vliet and McAllister 1994, Piatt and Anderson 1996, Kuletz et al. 2003).

The overall goal of this study was to gather information for developing a long-term monitoring plan for Kittlitz's Murrelets that would result in reliable trend estimates with appropriate levels of precision for conservation planning. Specifically, our objectives were to estimate the population size and identify factors that influenced abundance of Kittlitz's Murrelets across space and time. We employed a combination of conventional sampling methods and spatial modeling to extract biological information from at-sea count data, primarily used to estimate abundance, and to investigate the implications of monitoring populations in such a highly dynamic environment. We then simulated a Kittlitz's Murrelet population to examine power to detect trend assuming different degrees of variation and detection probabilities.

\section{STUdy AREA}

We studied Kittlitz's Murrelets in Icy Bay $\left(60^{\circ} 01^{\prime} \mathrm{N}\right.$, $141^{\circ} 20^{\prime} \mathrm{W} ; 110 \mathrm{~km}$ northwest of Yakutat, Alaska, USA; Fig. 1). In the late 19th century, this area was completely covered by a glacier; more than $40 \mathrm{~km}$ of glacial retreat occurred in the 20th century, exposing Icy Bay and its tributary fjords (Barclay et al. 2006). Today, Icy Bay is $\sim 240 \mathrm{~km}^{2}$ and comprises a shallow outer bay, which is adjacent to the Gulf of Alaska and the Alaska Current, and a deep inner bay. Four fjords radiate from inner Icy Bay and each has an active tidewater glacier at its head (Guyot, Yahtse, Tsaa, and Tyndall; Fig. 1). Although the Tyndall Glacier appears to have stabilized recently (Koppes and Hallet 2006), it has retreated nearly $18 \mathrm{~km}$ since 1961 (roughly $0.45 \mathrm{~km} /$ year), forming Taan Fjord. The other three tidewater glaciers are considered to be in stable retracted positions (Porter 1989). The bordering Malaspina Glacier (Fig. 1), a piedmont glacier that empties into Icy Bay via the Caetani River, is thinning (Arendt et al. 2002). Icy Bay has a maritime climate with mean temperatures of $-3.4^{\circ} \mathrm{C}$ in January and $12.0^{\circ} \mathrm{C}$ in 
July, and a mean annual precipitation of $407 \mathrm{~cm}$ (National Climatic Data Center, Yakutat, 1971-2000).

During our study, we subdivided Icy Bay into two distinct geographical units: Inner Main Bay (hereafter, Main Bay; $110 \mathrm{~km}^{2}$ ) and Taan Fjord $\left(24 \mathrm{~km}^{2}\right)$. The other three fjords were not consistently accessible due to ice pack and floes, although we opportunistically surveyed and scanned open water leads in these areas when conditions allowed. Main Bay is relatively shallow (range $52-120 \mathrm{~m}$ ) with a large shoal $\sim 6 \mathrm{~m}$ deep extending along the southeastern shoreline and one marine sill that bisects the bay. Taan Fjord is deeper (range $70-138 \mathrm{~m}$ ) and has a tidewater glacier at its terminus and two glacial sills at the entrance and midfjord. During our surveys, sea surface temperature averaged $8.9^{\circ} \mathrm{C}$ (range $3.4-12.6^{\circ} \mathrm{C}$ ) in Main Bay and $6.9^{\circ} \mathrm{C}$ (range $3.1-12.1^{\circ} \mathrm{C}$ ) in Taan Fjord. Water clarity in Taan Fjord (mean $0.99 \mathrm{~m}$; range $0.10-2.10 \mathrm{~m}$ ) and Main Bay (mean $0.99 \mathrm{~m}$; range $0.10-1.70 \mathrm{~m}$ ) was similar.

\section{Methods}

\section{Survey design and data collection}

We conducted at-sea surveys in Icy Bay from 2 July to 5 August 2005. We selected these dates to coincide with the suspected peak period of after-hatch-year (AHY) birds and fledging of hatch-year (HY) birds in southeast Alaska (Day 1996). We established two types of transects (shoreline and pelagic) in each of the two geographic units (Main Bay, Taan Fjord), resulting in a total of four sampling strata (Main Bay shoreline, Main Bay pelagic, Taan Fjord shoreline, and Taan Fjord pelagic). Shoreline transects were $200 \mathrm{~m}$ wide and paralleled the shore. Pelagic transects were perpendicular to shore, $\sim 2 \mathrm{~km}$ apart, varied in length according to the width of the bay or fjord, and ended $200 \mathrm{~m}$ from shore (following Kuletz and Kendall 1998). We conducted surveys during five one-week survey periods. Due to time constraints, ice barriers, and difficult sea conditions, survey effort in Main Bay and Taan Fjord varied, but we attempted to maintain our spatial coverage throughout all survey periods. We completed surveys in each sampling strata in a single day to avoid double-counting murrelets. We attempted to alternate direction and order of transects for each survey, provided that ice and weather conditions allowed for safe boat navigation.

We surveyed between 07:00 and 21:00 hours using a $5.5-\mathrm{m}$ boat moving at a speed of $\sim 10 \mathrm{~km} / \mathrm{h}$. Each survey utilized two observers and one boat driver. For both shoreline and pelagic surveys, observers recorded all Brachyramphus murrelets within an unlimited distance on either side of the boat and $300 \mathrm{~m}$ ahead of the boat. For each observation, we recorded group size, age category, location (air or water), and distance (m) to the group. Based on plumage characteristics, we categorized each Kittlitz's Murrelet as definite AHY (after hatch year), probable AHY, unknown, probable HY (hatch year), or definite HY (following Kuletz and Kendall 1998). We recorded depth ( $\mathrm{m}$; assumed to be a surrogate for prey availability), sea conditions (Beaufort scale), weather, ice cover (\%), and swell height every 30 minutes or as conditions changed. We did not conduct surveys if weather conditions were unacceptable (Beaufort scale $>2$ ). We recorded data using a voice-activated recording system that was integrated with a GPS unit, which stamped each observation with a location and time (for details, see Fischer and Larned [2004]).

Tidal influence at each observation was categorized by tidal stage, which represented vertical movement of water, as ebb or flood. Tidal current strength, which represented horizontal movement of water, was also estimated using the same method as Day and Nigro (2000; rule of twelfths) with one modification: we multiplied relative current tidal strength by maximum tidal height during the tidal cycle to better account for current velocity and strength.

\section{Data analyses}

Murrelet abundance across space and time.-We estimated abundance of Kittlitz's Murrelets during each survey period in each of the four strata, but treated shoreline and pelagic strata separately because we could not assume that the distribution of birds was uncorrelated with transects in the shoreline strata and because sampling intensity varied among strata. Abundance was estimated using standard distance sampling methods (Buckland et al. 2001).

To estimate abundance in pelagic strata, we fit distance data collected on pelagic transects using Program DISTANCE (Thomas et al. 2006). We truncated observations at $300 \mathrm{~m}$ and then binned them in 50-m intervals. We fit the binned data to three detection functions and evaluated the influence of sea condition, swell height, weather condition, and ice cover on detection probability (Buckland et al. 2001). Based on the minimum Akaike's Information Criterion value, we selected the best model to estimate detection probability, which included the weather (wea) covariate $\left(\hat{\beta}_{\text {wea }} \pm \mathrm{SE}=0.16 \pm 0.07\right.$; Burnham and Anderson 2002). With increased cloud cover, the probability of detection also increased, presumably due to less glare from the sun and water. We computed encounter rate variance based on the empirical variance in transect counts to avoid assuming a Poisson variance across transects (Buckland et al. 2001).

In shoreline strata, we were unable to fit a detection function to the data because the distribution of birds was correlated with the shoreline and transects paralleled the shoreline. Therefore, we used the best selected model from the distance sampling results in pelagic strata (described previously) to estimate the detection probability for the shoreline strata by recalculating the integral of the detection function out to $100 \mathrm{~m}$ from the boat for each bird detected, including the weather covariate value for that detection. We then computed 
abundance within $200 \mathrm{~m}$ of the shoreline (shor) or shallowest navigable water by summing the count of observed Kittlitz's Murrelets in that area and dividing by the average detection probability for each bird:

$$
\hat{N}_{\text {shor }}=\sum_{i=1}^{n} \frac{1}{\hat{P}_{i}}
$$

where $\hat{P}_{i}$ is the estimated detection probability of the $i$ th bird and $n$ is the number of birds detected in the shoreline stratum. The sampling covariance matrix of estimated shoreline abundance was then computed from the detection probability function parameters and their covariance matrix using the delta method (Williams et al. 2002). The density of Kittlitz's Murrelets from shoreline surveys was estimated by dividing abundance by the area within $200 \mathrm{~m}$ of the shoreline. The sampling variance of estimated density was also computed using the delta method.

Understanding abundance patterns.-We built spatial models to describe the distribution and identify factors influencing abundance of Kittlitz's Murrelets throughout Icy Bay at each survey period. We split all surveyed transects and shorelines into $200 \times 200 \mathrm{~m}$ cells. We calculated the abundance of Kittlitz's Murrelets within each cell by dividing the count of murrelets in each cell at each survey period by the detection probability from the distance sampling results. We then fit the count model of Hedley and Buckland (2004) to the spatial data. We chose to use this model because it was developed for use with line transect data as opposed to other methods that have been developed for points (e.g., Royle et al. 2004). We used a generalized additive model form of the count model with a two-dimensional smoothing function on location (latitude and longitude) and linear functions on depth, ice cover, tidal stage, and tidal current strength (Hedley and Buckland 2004: Eq. 3.4). A log-link function was used with a quasi-Poisson error structure. We developed a set of 18 possible models and used deviance values and generalized crossvalidation scores to aid in model selection. Models were fit in R ( R Development Core Team 2006) with the MGCV package (Wood 2004).

Implications for monitoring.-We determined the amount of survey effort in kilometers of transects required to achieve varying levels of precision ranging from $5 \%$ to $50 \%$ coefficients of variation (CV), using the effort formula provided in Buckland et al. (2001), which includes empirical estimates of spatial overdispersion. We then calculated the power to detect a decline of $5 \%$ and $10 \%$ per year in Kittlitz's Murrelet density, given spatial variation with a CV of $25 \%$ and $50 \%$ and detection probability variation ranging from a CV of $5 \%$ to $30 \%$. We considered power to detect trend for a monitoring duration of 5-40 years by simulating a Kittlitz's Murrelet population and its trend through time, and sampling from it. The simulation included process variation in Kittlitz's Murrelet population size in addition to sampling variation. For each repetition of the simulation, an initial population of murrelets was generated based on our study results. Then the population was allowed to change through time based on an average decline rate $(5 \%$ or $10 \%)$ selected from a normal distribution with mean equal to the decline rate and variance equal to 0.002 . The simulated population was sampled each year, with the variation in detection probability and encounter rate variation such that the estimated density for a given year was a random normal variable with mean equal to the true density and variance equal to the sampling variance specified for that simulation. We fit a log-linear trend weighted by the inverse of the variance of each $\log$ (density) estimate to each simulated survey and determined if that estimated trend was statistically less than zero $(P<0.05)$. We performed 500 simulation replicates for each combination of rate of decline, spatial variation, detection probability variation, and number of years. We performed the analyses in $\mathrm{R}$ ( $\mathrm{R}$ Core Development Team 2006; Supplement).

\section{RESULTS}

\section{Murrelet abundance across time and space}

During the five-week period, we recorded 880 Brachyramphus murrelets, of which 794 (90\%) were Kittlitz's Murrelets (Table 1). The majority (98\%) of Kittlitz's Murrelets observed were definite "after-hatchyear" (AHY) birds; only 10 were categorized as probable AHY and nine were probable "hatch-year" (HY) birds. The overall population estimate $(N$, mean \pm SE) during the peak period (3-9 July) was $1317 \pm 294$ birds, decreasing to $68 \pm 37$ birds by the last survey period (31 July-6 August). The highest densities of Kittlitz's Murrelets were recorded in Taan Fjord during the first two survey intervals (Fig. 2). However, CVs for Taan Fjord (34-63\%) were also higher compared to those in Main Bay (16-55\%) due to the spatial clumping along a few transects in Taan Fjord. Densities in Taan Fjord and Main Bay abruptly decreased ( $-40 \%$ and $-55 \%$, respectively) after the second survey period (Fig. 2). The percentage of $200 \times 200 \mathrm{~m}$ cells with at least one Kittlitz's Murrelet was consistently higher across survey periods in Taan Fjord compared to the Main Bay (Table 1). Average group size over all survey periods was 1.65 birds.

\section{Understanding abundance patterns}

Spatial models revealed several temporal shifts in abundance and high-density "hotspots," or bumps in the response surface that identify areas of relatively high density, at a fine spatial scale (Fig. 3). In the first survey period, birds were concentrated near the eastern side of the mouth of Icy Bay, but had shifted almost completely into Taan Fjord during the second survey period and remained there through the third and fourth survey periods. By the fourth survey period, very few birds remained in the Main Bay and the fifth survey period 
TABLE 1. Summary statistics describing survey effort, detections, and distribution of Brachyramphus murrelets by survey period, 3 July-6 August 2005, Icy Bay, Alaska, USA.

\begin{tabular}{|c|c|c|c|c|c|c|c|c|c|c|}
\hline \multirow{3}{*}{$\begin{array}{l}\text { Survey } \\
\text { period }\end{array}$} & \multicolumn{2}{|c|}{$\begin{array}{l}\text { Pelagic } \\
\text { transects }\end{array}$} & \multirow{3}{*}{$\begin{array}{c}\begin{array}{c}\text { Shoreline } \\
\text { transects }\end{array} \\
\begin{array}{c}\text { Length } \\
\text { surveyed }(\mathrm{km})\end{array}\end{array}$} & \multirow{2}{*}{\multicolumn{3}{|c|}{$\begin{array}{c}\text { Total } \\
\text { detections } \\
\text { by species }\end{array}$}} & \multicolumn{2}{|c|}{$\begin{array}{l}\text { Cells occupied } \\
\text { (\%, KIMU } \\
\text { only })^{\dagger}\end{array}$} & \multicolumn{2}{|c|}{$\begin{array}{l}\text { Overdispersion } \\
\text { factor } \\
\text { (KIMU only) } \dagger\end{array}$} \\
\hline & \multirow{2}{*}{$\begin{array}{l}\text { Length } \\
\text { surveyed } \\
(\mathrm{km})\end{array}$} & \multirow{2}{*}{$\begin{array}{c}\text { No. } \\
\text { transects }\end{array}$} & & & & & Inner & Таяา & Inner & Ta9n \\
\hline & & & & KIMU & MAMU & BRACH & Main Bay & Fjord & Main Bay & Fjord \\
\hline 1 & 64.561 & 16 & 0 & 198 & 0 & 26 & 17 & 30 & 1.7 & 3.8 \\
\hline 2 & 66.197 & 17 & 37.441 & 291 & 0 & 32 & 13 & 40 & 4.3 & 82.5 \\
\hline 3 & 63.109 & 15 & 92.56 & 203 & 13 & 6 & 7 & 29 & 0.5 & 10.7 \\
\hline 4 & 70.425 & 17 & 37.441 & 75 & 2 & 4 & 2 & 12 & 0.1 & 0.9 \\
\hline 5 & 12.615 & 7 & 37.441 & 27 & 1 & 2 & ns & 9 & ns & 0.4 \\
\hline
\end{tabular}

Note: Species are abbreviated as KIMU, Kittlitz's Murrelet; MAMU, Marbled Murrelet; and BRACH, Brachyramphus murrelet not identified to species.

$\dagger$ Not surveyed is denoted by "ns."

only produced a small number of birds in Taan Fjord. Although several "hotspots" were identified during all survey periods, the south entrance to Taan Fjord and mid-fjord repeatedly supported very high densities of Kittlitz's Murrelets.

The explanatory variables accounted for some of the variability in abundance across space (Table 2). Selected models included tidal current strength $(100 \%$ of the models), depth (60\%), and tide (20\%) as covariates; models containing ice cover were not selected (Tables 2 and 3). During the first three survey periods, tidal current strength was positively associated with murrelet abundance, and although this relationship was reversed during the last two survey periods, this was probably a result of low sample size. Depth influenced abundance inconsistently, with more murrelets in deeper waters during the first survey period and in shallower waters during the second survey period. Because the effect sizes were expressed on a log scale, they appear to be small; however, the magnitude relative to the precision of the parameter estimates from the selected models for the first three survey periods was reasonably strong (Table 3). During the fourth and fifth survey periods, the precision of the parameter estimates decreased, probably due to the few murrelets encountered during those surveys, and therefore, these results should be considered with caution. Percentage of deviance explained by the models increased with survey period as spatial complexity decreased.

\section{Implications for monitoring}

Rapid declines in survey effort were needed to achieve less precise estimates of population change. For example, the survey effort required to achieve a $\mathrm{CV}$ of less than 15-20\% increased rapidly. Target CVs of $10 \%$, $20 \%$, and $30 \%$ required surveying approximately 289 , 72 , and $32 \mathrm{~km}$ of transects, respectively. The effect of spatial variation was evident in the estimated power to detect trend (Fig. 4). Power to detect a decline changed substantially between the $25 \%$ and $50 \% \mathrm{CV}$ of spatial variation, but it changed little across the threefold difference in $\mathrm{CV}$ on detection probability. Power to detect an annual decline of $10 \%$ increased rapidly and reached 1.0 in just $10-15$ years, whereas an annual decline of 5\% increased more slowly, reaching a maximum in 20-25 years. Generally, all four scenarios resulted in high power $(>0.8)$ to detect a decline in 15-20 years, but the portion of the population remaining may be less than $20 \%$ of the initial population (Fig. 4).

\section{Discussion}

Currently, the cornerstone of many wildlife monitoring programs is an estimate of the abundance of a particular population. However, the complexity and inherent variation in organisms and their response to physical and biological factors at multiple scales make it difficult to estimate abundance and trend with high levels of precision and accuracy (Scott et al. 2002). Understanding these sources of variation not only can improve monitoring efforts, but also can provide information about the underlying ecological processes driving changes in the distribution and abundance of the species in question. This is particularly useful when evaluating conservation status and measures for species in decline, such as the Kittlitz's Murrelet.

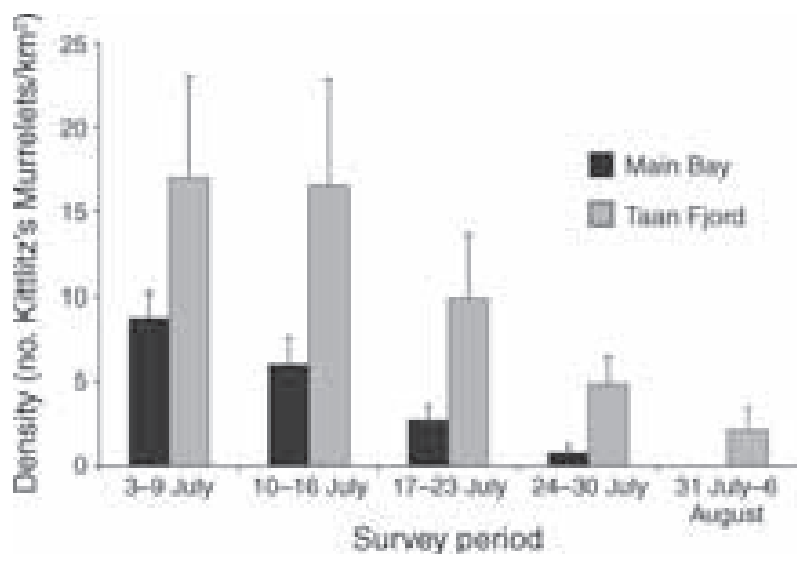

FIG. 2. Densities (no. $/ \mathrm{km}^{2}$; mean and SE) of Kittlitz's Murrelets in two geographic units across five one-week survey periods, Icy Bay, Alaska, 2005. 

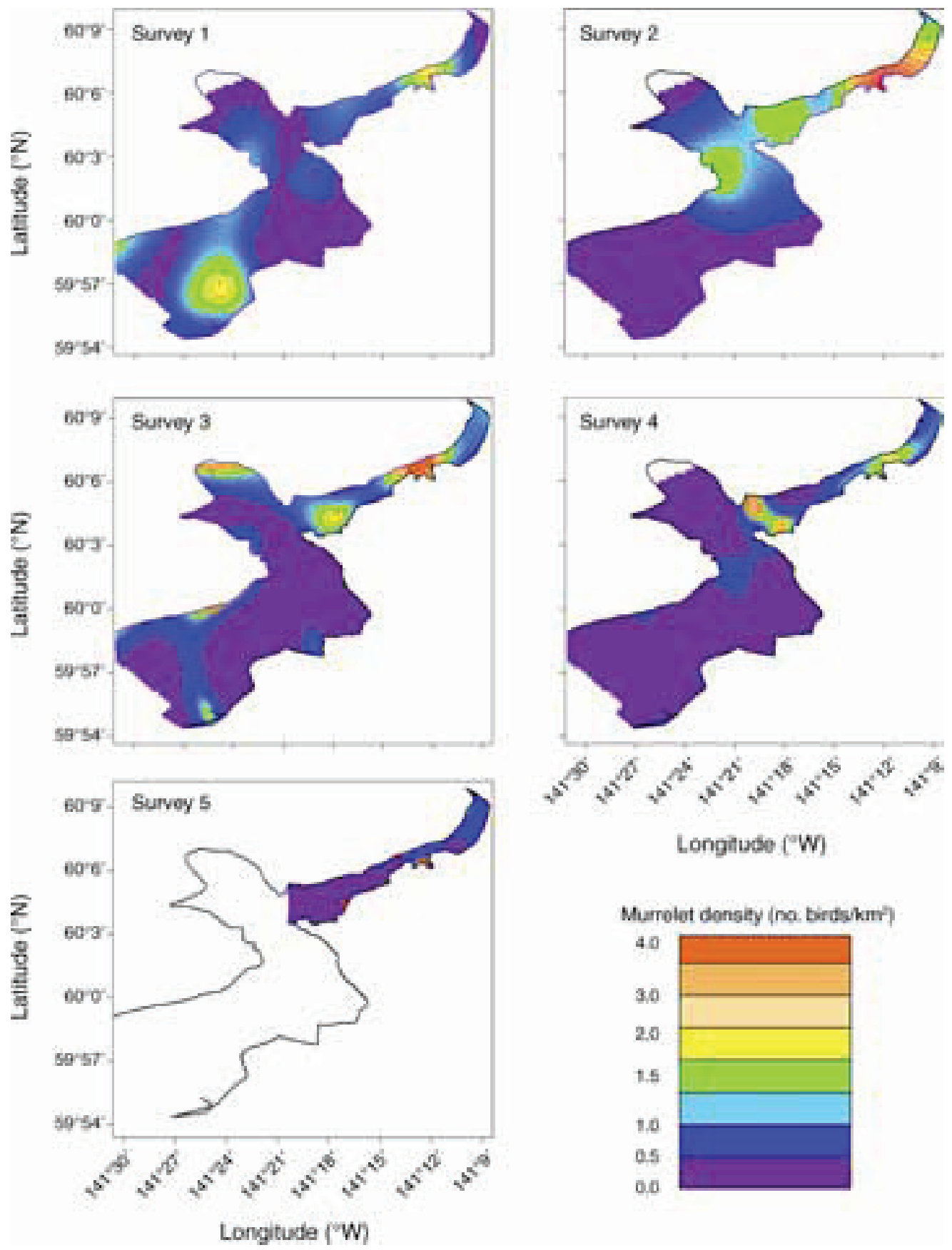

FIG. 3. Results of spatial models following Hedley and Buckland (2004) visually describing high densities of Kittlitz's Murrelets and temporal shifts in distribution, Icy Bay, Alaska, July 2005. Orange colors represent high densities, and blue colors represent low densities. The color scheme across all five panels is comparable.

\section{Murrelet abundance across time and space}

Based on our results, the population in Icy Bay (1317 \pm 294 birds) represents $5-16 \%$ of the estimated world population (range 8114-28179 birds; U.S. Fish and Wildlife Service 2005). Although higher population estimates exist for Glacier Bay (2265; range 13493181), Prince William Sound (2022; range 919-3125), and the southern Alaska Peninsula (2265; range 11654405), these areas are significantly larger in size compared to Icy Bay (U.S. Fish and Wildlife Service 2005). As a result, Kittlitz's Murrelet densities estimated during this study, particularly in Taan Fjord, are among the highest ever recorded for this species. The only area with similar densities consistently is Harriman Fjord, Prince William Sound, where this species has declined since 1989 (Kuletz et al. 2003).

The apparent decline of Kittlitz's Murrelets has been linked to the retreat of tidewater glaciers in Alaska (Day et al. 1999, 2003, Kuletz et al. 2003), but the mechanistic 
TABLE 2. Candidate models and model selection statistics used to identify factors influencing abundance of Kittlitz's Murrelets across five one-week survey period in Icy Bay, Alaska, July 2005.

\begin{tabular}{|c|c|c|c|c|c|c|c|c|c|c|}
\hline \multirow[b]{2}{*}{ Model } & \multicolumn{2}{|c|}{ Survey period 1} & \multicolumn{2}{|c|}{ Survey period 2} & \multicolumn{2}{|c|}{ Survey period 3} & \multicolumn{2}{|c|}{ Survey period 4} & \multicolumn{2}{|c|}{ Survey period 5} \\
\hline & $\begin{array}{c}\text { Deviance } \\
(\%)\end{array}$ & $\mathrm{GCV} \dagger$ & $\begin{array}{c}\text { Deviance } \\
(\%)\end{array}$ & $\mathrm{GCV} \dagger$ & $\begin{array}{c}\text { Deviance } \\
(\%)\end{array}$ & $\mathrm{GCV} \uparrow$ & $\begin{array}{c}\text { Deviance } \\
(\%)\end{array}$ & $\mathrm{GCV} \dagger$ & $\begin{array}{c}\text { Deviance } \\
(\%)\end{array}$ & $\mathrm{GCV}^{\dagger}$ \\
\hline Intercept only & 13.6 & 2.8716 & 36.1 & 3.1659 & 38.9 & 1.6201 & 44.5 & 0.7212 & 47.4 & 0.8217 \\
\hline Depth & 15.6 & 2.8276 & 36.3 & 3.1451 & 39.0 & 1.6231 & 45.7 & 0.7087 & 48.3 & 0.8182 \\
\hline Ice & 13.8 & 2.8756 & 36.1 & 3.1735 & 38.9 & 1.6237 & 44.6 & 0.7213 & 48.2 & 0.8239 \\
\hline Tide & 13.5 & 2.8772 & 36.1 & 3.1687 & 38.9 & 1.6239 & 45.4 & 0.7115 & 47.4 & 0.8286 \\
\hline TC & 13.5 & 2.8766 & 36.2 & 3.1671 & 39.3 & 1.6150 & 44.5 & 0.7231 & 47.4 & 0.8292 \\
\hline Ice + depth & 15.6 & 2.8330 & 36.3 & 3.1527 & 39.0 & 1.6266 & 45.9 & 0.7083 & 49.0 & 0.8176 \\
\hline Ice + tide & 13.7 & 2.8805 & 36.1 & 3.176 & 39.0 & 1.6275 & 45.5 & 0.7121 & 48.4 & 0.8287 \\
\hline Ice + TC & 13.7 & 2.8811 & 36.2 & 3.1743 & 39.3 & 1.6189 & 44.6 & 0.7231 & 48.2 & 0.8310 \\
\hline Tide + TC & 13.4 & 2.8816 & 36.2 & 3.1736 & 39.3 & 1.6190 & 45.7 & 0.7096 & 54.2 & 0.7649 \\
\hline Tide + depth & 15.5 & 2.8338 & 36.4 & 3.1462 & 39.0 & 1.6268 & 46.4 & 0.7017 & 48.4 & 0.8232 \\
\hline Depth + TC & 15.5 & 2.8338 & 36.6 & 3.1413 & 39.3 & 1.6179 & 45.7 & 0.7104 & 48.3 & 0.8253 \\
\hline $\mathrm{Ice}+$ tide $+\mathrm{TC}$ & 13.6 & 2.8853 & 36.2 & 3.1808 & 39.3 & 1.6229 & 45.8 & 0.7101 & 48.6 & 0.8212 \\
\hline Ice + depth + tide & 15.5 & 2.8393 & 36.5 & 3.1538 & 39.0 & 1.6303 & 46.5 & 0.7020 & 49.3 & 0.8183 \\
\hline Ice + depth + TC & 15.5 & 2.8392 & 36.6 & 3.1489 & 39.3 & 1.6218 & 45.9 & 0.7099 & 49.1 & 0.8233 \\
\hline Depth + tide + TC & 15.5 & 2.8402 & 36.6 & 3.1481 & 39.3 & 1.6220 & 46.8 & 0.6981 & 50.1 & 0.8079 \\
\hline Ice + depth + tide + TC & 15.5 & 2.8457 & 36.6 & 3.1557 & 39.3 & 1.6259 & 46.9 & 0.6981 & 50.7 & 0.8084 \\
\hline Ice $\times$ TC & 13.8 & 2.8853 & 36.2 & 3.1786 & 39.3 & 1.6227 & 45.3 & 0.7167 & 52.3 & 0.8038 \\
\hline Depth $\times$ TC & 16.0 & 2.8252 & 36.6 & 3.1489 & 39.3 & 1.6220 & 46.3 & 0.7043 & 48.3 & 0.8337 \\
\hline
\end{tabular}

Notes: Covariates considered in the set of candidate models included depth (m), ice cover (Ice, \%), tidal stage (Tide); and tidal current strength (TC). We used a log-link function in the generalized additive model. The interactive terms are denoted with a multiplication sign $(\times)$, and additive terms are indicated with an addition sign $(+)$. Boldface indicates the model selected for the respective survey period.

$\dagger$ Generalized cross-validation (GCV) scores.

understanding of this relationship is unresolved. Of the four fjords in Icy Bay, we found high densities of Kittlitz's in Taan Fjord, the only fjord with a recently retreating tidewater glacier, and an absence of birds (when ice conditions permitted access) in the three fjords with stable tidewater glaciers (Porter 1989). Although ice often blocked us from systematically surveying these three fjords, we scanned open water leads and did not detect any Kittlitz's Murrelets in the leads or near the face of the glaciers. Our results contradict those found by Kuletz et al. (2003), who concluded that Kittlitz's Murrelets were positively associated with stable and advancing glaciers, such as those in Harriman Fjord, and nearly disappeared from fjords with retreating tidewater glaciers. The authors hypothesized that increased sedimentation due to glacial ablation may reduce availability of phytoplankton and macrozooplankton and therefore decrease abundance of invertebrates and forage fish (Kuletz et al. 2003). We believe that there is merit to this hypothesis; the rapid retreat of the Tyndall Glacier at the head of Taan Fjord has produced some of the highest short-term sedimentation rates every reported (Porter 1989). Yet, in Icy Bay the value of Taan Fjord relative to the Main Bay and other three fjords for Kittlitz's Murrelets cannot be overstated. We conclude that generalizations regarding the relationship between glacier status and Kittlitz's Murrelet abundance may result in faulty inferences.

TABLE 3. Summary of model statistics identifying factors influencing abundance of Kittlitz's Murrelets across five one-week survey periods in Icy Bay, Alaska, July 2005.

\begin{tabular}{cllc}
\hline \hline $\begin{array}{c}\text { Survey } \\
\text { period }\end{array}$ & Selected model & \multicolumn{1}{c}{ Parameter estimates $\pm \mathrm{SE}$} & $\begin{array}{c}\text { Deviance } \\
(\%)\end{array}$ \\
\hline 1 & depth $\times$ TC & depth $=0.0078 \pm 0.0023$ & 16.0 \\
& & $\begin{array}{l}\text { TC }=0.0520 \pm 0.0395 \\
\text { depth } \times \text { TC }=-0.0003 \pm 0.0002\end{array}$ & \\
& depth $=-0.0022 \pm 0.0007$ & 36.6 \\
2 & depth + TC & TC $=0.0292 \pm 0.0189$ & 39.3 \\
& TC & depth $=-0.0201 \pm 0.0093$ & 46.8 \\
4 & depth + tide + TC & tide $=1.8117 \pm 0.4759$ & \\
& & TC $=-0.0488 \pm 0.0192$ & 54.2 \\
5 & tide $=10.9943 \pm 3.8351$ & \\
& & TC $=-0.4398 \pm 0.1638$ &
\end{tabular}

Notes: Covariates considered in the set of candidate models included depth (m), ice cover (\%), tidal stage (tide); and tidal current strength (TC). We used a log-link function in the generalized additive model. The interactive term is denoted with a multiplication sign $(\times)$, and additive terms are indicated with an addition sign $(+)$. 

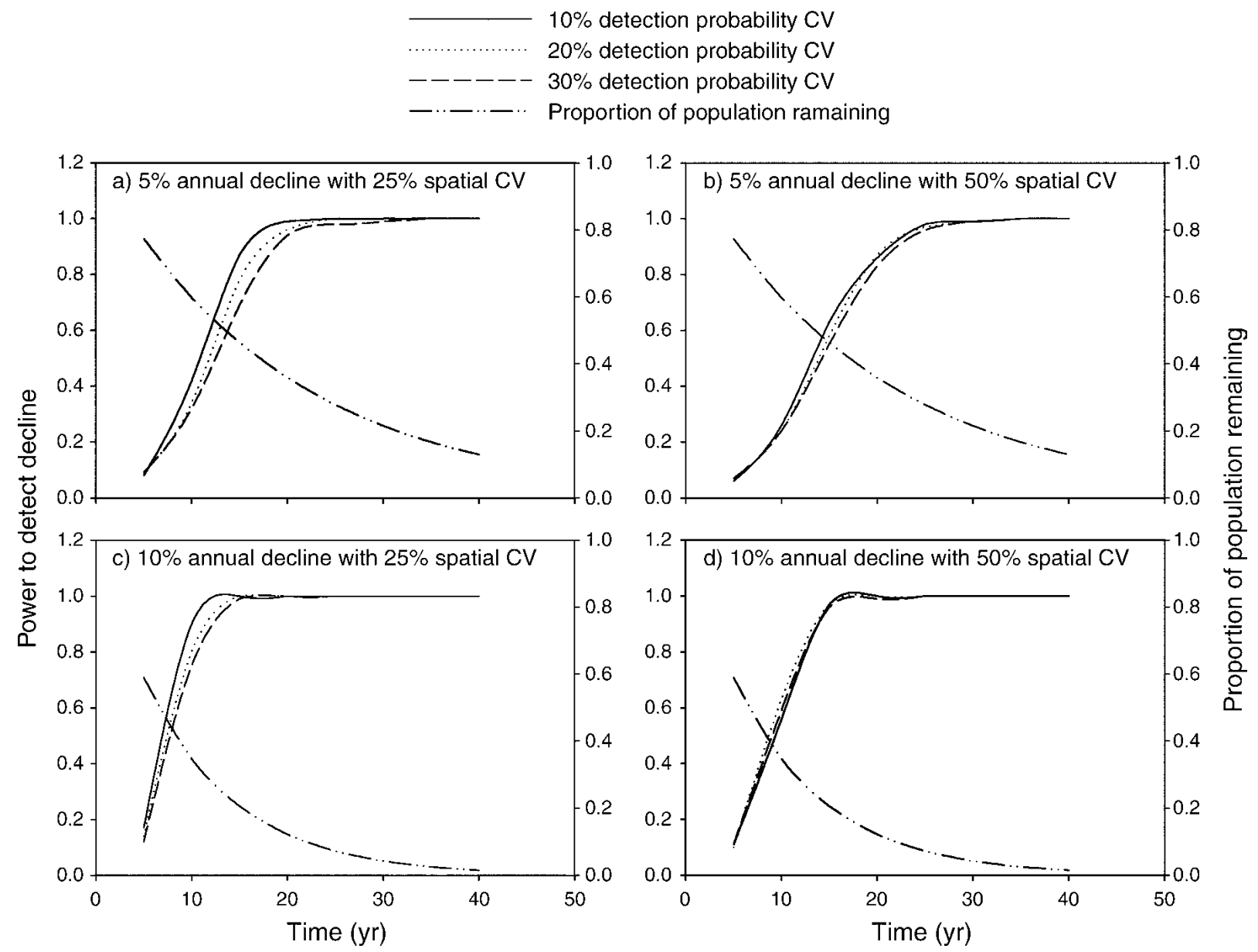

Fig. 4. Results of power simulations to detect (a, b) 5\% and (c, d) 10\% annual declines of Kittlitz's Murrelets, assuming spatial variation with (a, c) $25 \%$ and (b, d) $50 \%$ CVs. Simulations were based on data collected during the breeding season in Icy Bay, Alaska, 2005.

\section{Understanding abundance patterns}

Building spatial models from our survey data provided insight into the spatial variability of Kittlitz's Murrelets and factors that may influence at-sea distribution and abundance. Within a few weeks, birds shifted from deeper waters in the Main Bay to shallower waters in Taan Fjord, where they remained for nearly two weeks before abruptly departing the study area. Although the densities in Taan Fjord did not change much during this distribution shift (between the first and second survey periods), spatial models demonstrated that birds were more aggregated in Taan Fjord. These aggregations were centered on a few pelagic transects, increasing the transect-to-transect variation and, therefore, the standard errors and CVs in Taan Fjord. Regardless of survey period, densities in Taan Fjord were more than twice those in the Main Bay and the spatial aggregations in Taan Fjord were more pronounced than those in the Main Bay throughout the study.

One drawback to the Hedley and Buckland (2004) model we used was that we were unable to consider spatial autocorrelation in our analyses. We are unaware of a method that estimates spatial autocorrelation rigorously when the abundance estimates have a sampling correlation structure and there is a large amount of edge relative to interior area. As a result of not estimating spatial autocorrelation, our sampling variances are potentially underestimated. Hedley and Buckland (2004) recommend a bootstrap resampling procedure if predictions are to be made from the models that they present.

Of the explanatory variables that we evaluated, tidal current strength influenced murrelet abundance most consistently; murrelet abundance increased with strong currents. Tidal current strength has been shown to influence the abundance of other foraging seabirds (Schneider et al. 1987, Coyle et al. 1992). Although Day and Nigro (2000) concluded that foraging Kittlitz's Murrelets were associated with shoals and marine sills, not with strong, tidally induced currents, we believe that the interaction of these physical features best explains Kittlitz's Murrelet abundance. Foraging Marbled Murrelets associate with bathymetric features that promote upwelling and currents, including underwater 


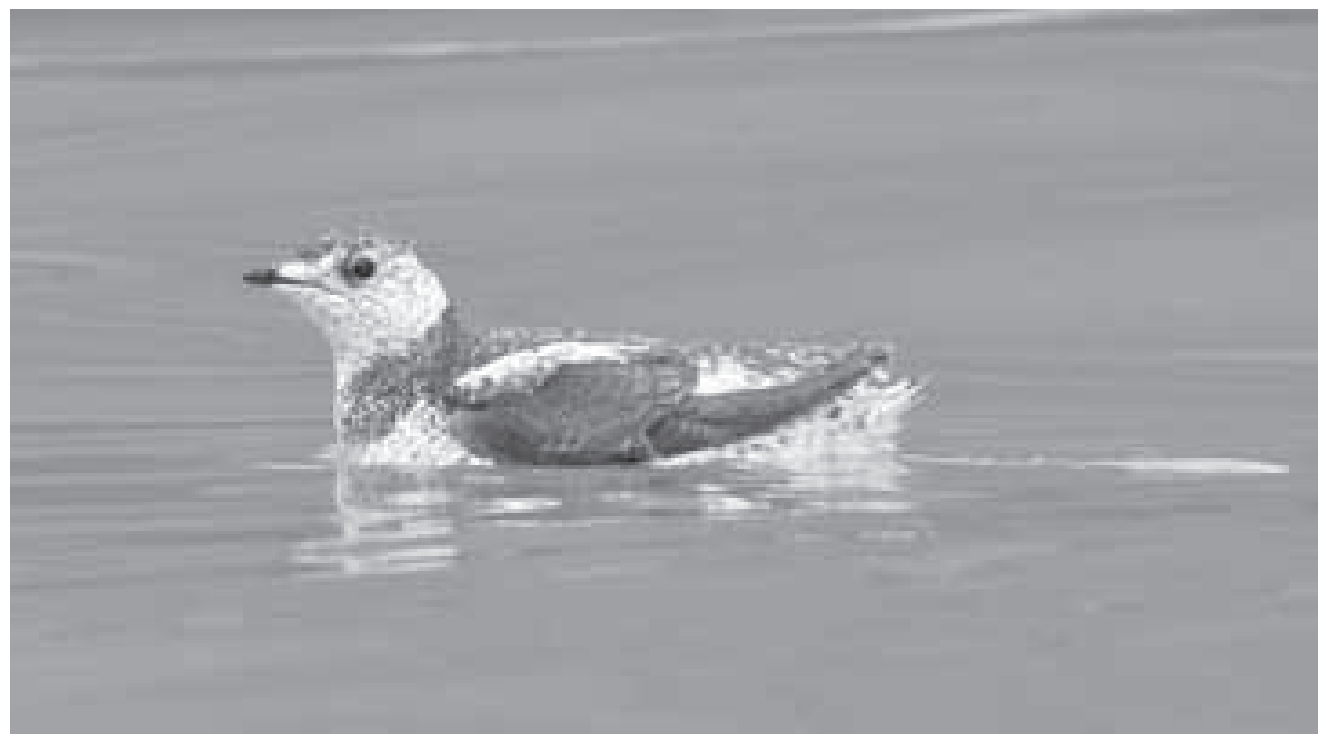

Plate 1. Photograph of Kittlitz's Murrelet in pre-basic molt taken on 27 July 2005 in Icy Bay, Alsaka (USA). Photo credit: Mason Reid/NPS.

shelves and mouths of side bays (Kuletz 2005). In this study, we observed the highest densities of Kittlitz's Murrelets in mid-Taan Fjord and near the mouth of Taan Fjord. Both hotspots were in close proximity to a shallow shoal with an adjacent submarine ridge, which probably interacted with strong tidal currents to create local upwelling, tidal rips, and eddies that, in turn, aggregated prey (Coyle et al. 1992). Given the complex marine environment, particularly in these glacial systems, we expect that the explanatory variables we evaluated covaried. Although this potentially affected the variance estimates, it probably did not affect the parameter estimates. In the future, we recommend modeling the covariance structure of the explanatory variables.

Our study was not designed to test reasons for the decline of Kittlitz's Murrelets. However, our results emphasize the importance of the horizontal movement of water and the vertical mixing of the horizontal layers in combination with underwater shelves and glacial sills. These physical characteristics were present in Taan Fjord where we often observed fast-moving ice, indicative of strong current, allowing us to survey this area repeatedly. In contrast, ice pack accumulated in Tsaa, Guyot, and Yahtse Fjords and remained there for several days and sometimes weeks, permitting us to survey these fjords only 1-2 times over all survey periods. Ice floes in Taan Fjord were carried from the face of the glacier and out of the fjord by swift currents that we attributed to the massive water discharge from the Tyndall Glacier. Motyka et al. (2003) estimated velocities of water discharge at tidewater glaciers ranging from $0.45-1.86 \mathrm{~km} / \mathrm{h}$. This discharge comprised of seawater from upwelling, submarine ice melt, and subglacial waters can contribute nearly $4000 \mathrm{~m}^{3} / \mathrm{s}$ into the system and tends to be greatest from rapidly retreating glaciers (Motyka et al. 2003). The constant water flow near the face of the glacier creates localized upwelling and mixes the water column (Motyka et al. 2003), which probably becomes more stratified as the water flows away from the glacier. We believe that water discharge from rapidly retreating glaciers, such as the Tyndall Glacier, plays an important role in current strength, local upwelling, gyres, water column stratification, and sediment deposition. We conclude that glacier status alone cannot be used to draw inferences about population declines of the Kittlitz's Murrelet, but instead should be combined with an understanding of the underlying ecological processes that define the biological thresholds of this species.

\section{Implications for monitoring}

Our results provide a substantial amount of information for planning future monitoring of Kittlitz's Murrelets in glacial fjords and protected bays. By using our empirically derived estimates of variation and detection probabilities to generate realistic bounds on parameter estimates, an optimal monitoring program can be generated. It is important to note that results of our power simulations were based on data collected in an area with a high density of Kittlitz's Murrelets. Recommendations provided below are suitable for areas with populations greater than 1000 birds or with peak densities greater than 5 birds $/ \mathrm{km}^{2}$. Given the magnitude of decline documented over the last 20 years and the lack of knowledge about this species, we also recommend monitoring areas with smaller populations and lower densities, but monitoring guidelines based on actual survey data should be developed first.

Depending on objectives of specific monitoring programs, we recommend conducting at-sea surveys during peak abundance of murrelets to increase the 
precision of estimates and therefore power to detect trend. The range of peak abundance probably differs by geographic area and should be determined prior to monitoring efforts. Using two boats to conduct surveys simultaneously would reduce temporal variation and would likely reduce the $\mathrm{CV}$. We suggest conducting at least two surveys annually in areas where precise trend estimates are desired until more is known about interannual variation in abundance.

Although our study did not explicitly evaluate implications of sampling design (see Rachowicz et al. 2006), spatial variation of Kittlitz's Murrelets strongly influenced the power to detect population trend. Our results suggest that surveying a minimum of $50 \mathrm{~km}$ of transects, regardless of the size of the study area, will result in an acceptable $\mathrm{CV}$ of $25 \%$. Given the extreme spatial aggregation of Kittlitz's Murrelets, we recommend a survey design that includes relatively short transects (assuming fixed transect length) $\sim 2 \mathrm{~km}$ apart to avoid birds moving from one transect to the next and crossing known changes in density (e.g., perpendicular to the shoreline) to reduce transect-to-transect variation. A spatial analysis such as the one reported here can help determine where density gradients may exist. In glacial fjords, we suggest a predefined layout of transects beyond (inland of) the face of the glacier in the event that glacial recession or lack of ice pack results in increased marine habitat for murrelets.

Without knowing true population size (which is nearly impossible), it is difficult to quantify bias associated with methods for estimating population size and trend in the field. Distance sampling methods provide empirical estimates of detection probability, which account for potentially confounding effects associated with weather, observer, and sea conditions. Variability of detection probabilities was negligible compared to spatial variation when estimating trend over 5-40 years, and therefore the benefit of incorporating detection probabilities far outweighs the cost to the precision of abundance estimates. We advise using population size as the metric of interest for monitoring long-term population trends of Kittlitz's Murrelets, as opposed to using density, because ice conditions may preclude surveying all transects each year and, based on our experience, murrelets very rarely occur in areas with thick ice cover. During surveys with heavy ice pack, murrelets will probably crowd into the limited areas of open water, resulting in high estimates of density (birds $/ \mathrm{km}^{2}$ ). In contrast, densities of murrelets are likely to be lower during surveys with little ice cover. Therefore, an increase or decrease in density may not be indicative of the same trend in the population. This is in contrast to species that live in relatively static environments where density and abundance convey the same information simply scaled by area. In the future, we recommend better understanding of potential biases associated with estimating trends of Kittlitz's Murrelets in areas with dynamic ice conditions.
Surveying Kittlitz's Murrelets at sea is economical, repeatable, and defensible and, therefore, will probably continue to be the foundation for long-term monitoring programs. However, shifting spatial gradients resulting from changes in physical and biological processes influence murrelet distribution and can complicate trend estimation. Mechanistic understanding and quantification of processes that influence murrelet distribution and abundance will strengthen interpretation of trend, provided that monitoring efforts result in the least biased and most precise population estimates. Based on results from this study, the design previously described would have high power $(>0.9)$ to detect a trend of $5 \%$ annual decline in 15 years, which is encouraging, given the magnitude of the apparent decline and the current conservation status of this species. Although the results of this study are species specific, we believe that our approach to designing a successful monitoring program by using conventional sampling methods and spatial modeling is applicable to other species for which there is insufficient information, yet pressing conservation concern.

\section{ACKNOWLEDGMENTS}

We thank the National Park Service and U.S. Fish and Wildlife Service for funding and logistical support of this project. Kathy Kuletz, Robert Day, Marc Romano, and Jeffrey Bromaghin provided useful comments during project development. We are particularly grateful to Daniel Harrington for his superior assistance in the field and George and Jill Davis for their hospitality and watchful eye. Alsek Air and Yakutat Coastal Airlines provided support in the field. We thank two anonymous reviewers for useful comments on early drafts of this manuscript.

\section{Literature Cited}

Arendt, A. A., K. A. Echelmeyer, W. D. Harrison, C. S. Lingle, and V. B. Valentine. 2002. Rapid wastage of Alaska's glaciers and their contribution to rising sea level. Science 297: 382-386.

Barclay, D. J., J. L. Barclay, P. E. Calkin, and G. C. Wiles. 2006. A revised and extended Holocene glacial history of Icy Bay, southern Alaska, U.S.A. Arctic, Antarctic, and Alpine Research 38:153-162.

Buckland, S. T., D. R. Anderson, K. P. Burnham, J. L. Laake, D. L. Borchers, and L. J. Thomas. 2001. An introduction to distance sampling: estimating abundance of biological populations. Oxford University Press, Oxford, UK.

Burnham, K. P., and D. R. Anderson. 2002. Model selection and inference: a practical information-theoretic approach. Springer-Verlag, New York, New York, USA.

Coyle, K. O., G. L. Hunt, Jr., M. B. Decker, and T. J. Weingartner. 1992. Murre foraging, epibenthic sound scattering and tidal advection over a shoal near St. George Island, Bering Sea. Marine Ecology Progress Series 83:1-14.

Day, R. H. 1996. Nesting phenology of Kittlitz's Murrelets. Condor 98:433-437.

Day, R. H., K. J. Kuletz, and D. A. Nigro. 1999. Kittlitz's Murrelet Brachyramphus brevirostris. Number 435 in A. Poole and F. Gill, editors. The Birds of North America. American Ornithologists Union and Academy of Natural Sciences, Washington, D.C., and Philadelphia, Pennsylvania, USA.

Day, R. H., and D. A. Nigro. 2000. Feeding ecology of Kittlitz's and Marbled Murrelets in Prince William Sound, Alaska. Colonial Waterbirds 23:1-14. 
Day, R. H., D. A. K. Prichard, and D. A. Nigro. 2003 Ecological specialization and overlap of Brachyramphus murrelets in Prince William Sound, Alaska. Auk 120: 680-699.

Fischer, J. B., and W. W. Larned. 2004. Summer distribution of marine birds in the Western Beaufort Sea. Arctic 57:143-159.

Gomez de Segura, A., P. S. Hammond, A. Canadas, and J. A. Raga. 2007. Comparing cetacean abundance estimates derived from spatial models and design-based line transect methods. Marine Ecology Progress Series 329:289-299.

Hedley, S. L., and S. T. Buckland. 2004. Spatial models for line transect sampling. Journal of Agricultural, Biological and Environmental Statistics 9:181-199.

Koppes, M., and B. Hallet. 2006. Erosion rates during rapid deglaciation in Icy Bay, Alaska. Journal of Geophysical Research 111:1-11.

Kuletz, K. J. 2005. Foraging behavior and productivity of a non-colonial seabird, the marbled murrelet (Brachyramphus marmoratus), relative to prey and habitat. University of Victoria, Victoria, Canada.

Kuletz, K. J., and S. J. Kendall. 1998. A productivity index for marbled murrelets in Alaska based on surveys at sea. Journal of Wildlife Management 62:446-460.

Kuletz, K. J., S. W. Stephensen, D. B. Irons, E. A. Labunski, and K. M. Brenneman. 2003. Changes in distribution and abundance of Kittlitz's Murrelets (Brachyramphus brevirostris) relative to glacial recession in Prince William Sound, Alaska. Marine Ornithology 31:133-140.

Motyka, R. J., L. Hunter, K. A. Echelmeyer, and C. Connor. 2003. Submarine melting at the terminus of a temperate tidewater glacier, LeConte Glacier, Alaska, U.S.A. Annals of Glaciology 36:57-65.

Piatt, J. F., and P. Anderson. 1996. Response of common murres to the Exxon Valdez oil spill and long-term changes in the Gulf of Alaska marine ecosystem. American Fisheries Society Symposium 18:720-737.
Porter, S. C. 1989. Late Holocene fluctuations of the fjord glacier system in Icy Bay, Alaska, U.S.A. Arctic and Alpine Research 21:364-379.

R Development Core Team. 2006. R: A language and environment for statistical computing. R Foundation for Statistical Computing, Vienna, Austria. 〈http://www. R-project.org/>

Rachowicz, L. J., A. E. Hubbard, and S. R. Beissinger. 2006. Evaluating at-sea sampling designs for Marbled Murrelets using a spatially explicit model. Ecological Modelling 196: 329-344.

Royle, J. A., D. K. Dawson, and S. Bates. 2004. Modeling abundance effects in distance sampling. Ecology 85:15911597.

Schneider, D., N. M. Harrison, and G. L. Hunt, Jr. 1987. Variation in the occurrence of marine birds at fronts in the Bering Sea. Estuarine, Coastal, and Shelf Science 25:135-141.

Scott, J. M., P. J. Heglund, and M. L. Morrison. 2002. Predicting species occurrences: issues of accuracy and scale. Island Press, Washington, D.C., USA.

Thomas, L., J. L. Laake, S. Strindberg, F. F. C. Marques, S. T. Buckland, D. R. Anderson, K. P. Burnham, S. L. Hedley, J. H. Pollard, and J. R. B. Bishop. 2006. Distance 5 release 3. Research Unit for Wildlife Population Assessment, University of St. Andrews, St. Andrews, UK. 〈http://www.ruwpa. st-and.ac.uk/distance $\rangle$

Williams, B. K., J. D. Nichols, and M. J. Conroy. 2002. Analysis and management of animal populations. Academic Press, New York, New York, USA.

Wood, S. N. 2004. Stable and efficient multiple smoothing parameter estimation for generalized additive models. Journal of the American Statistical Association 99:673-686.

U.S. Fish and Wildlife Service. 2005. Species assessment and listing priority assignment form for Kittlitz's Murrelet. U.S. Fish and Wildlife Service, Anchorage, Alaska, USA.

van Vliet, G. B., and M. McAllister. 1994. Kittlitz's Murrelet: the species most impacted by direct mortality from the Exxon Valdez oil spill? Pacific Seabirds 21:5-6.

\section{SUPPLEMENT}

Simulation program code (Ecological Archives A017-088-S1). 